\title{
SIMULATING LARGE EMITTERS USING CMAQ AND A LOCAL SCALE FINITE ELEMENT MODEL. ANALYSIS IN THE SURROUNDINGS OF BARCELONA
}

\author{
Albert Oliver ${ }^{1}$, Raúl Arasa ${ }^{2}$, Agustí Pérez-Foguet ${ }^{3}$, and $M^{a}$ Ángeles González ${ }^{2}$ \\ ${ }^{1}$ University Institute for Intelligent Systems and Numerical Applications in Engineering (SIANI), \\ University of Las Palmas de Gran Canaria (ULPGC), Las Palmas de Gran Canaria, Spain \\ ${ }^{2}$ Technical Department, Meteosim S.L., Barcelona, Spain \\ ${ }^{3}$ Engineering Sciences \& Global Development (EScGD), University Research Institute for Sustainability \\ Science and Technology (IS.UPC), Department of Civil and Environmental Engineering, ETSECCPB, \\ Universitat Politècnica de Catalunya (UPC), Barcelona, Spain
}

\begin{abstract}
In this work, we compare two state of the art models to simulate large emitters in the local scale. The area of study is in the surroundings of Barcelona, where an important contributor to the SO2 levels is considered. The first modelling system uses the mesoscale meteorological model WRF-ARW, the Air Emission Model of Meteosim, AEMM, and the air quality model CMAQ. The second model is a one way nesting of the results from the first system in a subgrid Finite Element model; the results from the CMAQ simulation are used as initial and boundary conditions. The simulations have been carried out for one episode with high levels of SO2. The time period of the simulations is of $48 \mathrm{~h}$ with a $24 \mathrm{~h}$ spin-up.
\end{abstract}

Key words: Local scale, Air Quality Modelling, Large Emitters, WRF-CMAQ, Finite Element Method.

\section{INTRODUCTION}

Air quality is an environmental issue that affects directly to the population. According to the World Health Organization, it is estimated that air pollution affects much of the population, with 2.4 million deaths annually (EEA, 2007). For this reason the study of its impact, specially in urban areas is of vital importance.

Mescoscale air quality models are not enough to calculate the concentrations in the local scale that affect the health. For this reason efforts have been made to simulate the local scale using different techniques (Karamchandani et al. 2011). The most commonly used approaches are the nested grid, Plume-in-Grid (PinG), and hybrid models. The nested grid modelling is used in the U.S. Environmental Protection Agency models-3/CMAQ model (Byun et al. 2006). It uses grids with fine resolution in small domains within the larger domain, sometimes with more than one level of refinement. The Plume-in-Grid (PinG) model uses a puff or plume model in the grid model. The plume model simulates the subgrid scale processes and returns the solution to the grid model. So this technique is two-way. SCICHEM uses this technique and can be coupled to CMAQ (Karamchandani et al 2002, 2008). The hybrid models combines the solution from a coarse grid model and a local plume model. It is being used to model the population exposure to hazardous air pollutants, e.g. using CMAQ and the Hazardous Air Pollutant Exposure Model HAPEM (Rosenbaum 2005) to predict the exposure estimates (Isakov et al. 2007). This technique combines both solutions in a one-way approach, being this one the main difference with PinG.

In this work we propose two different sub-grid strategies and compare their results. The first strategy is an Eulerian coupled modelling system using the meteorological model WRF-ARW (Skamarock 2008), an emission model developed by Meteosim AEMM (Arasa 2013, 2014, 2016) and CMAQ. The other strategy is an adaptive, Eulerian, non-steady finite element model that uses the photochemical model of CMAQ (Oliver 2013). 


\section{METHODOLOGY}

In the following sections we show a more detailed description of the studied areas as well as the simulation domains and periods analysed and the modelling approach.

\section{Studied area}

The area of interest is in the surrounding of Barcelona. We will study the emission of a large emitter of SO2 in the atmosphere. In Fig. 1 we show the simulation domains used by the CMAQ modelling system. In Fig. 2 you can see a zoom of the smaller domain, and the location of the emitter, and the domain of the finite element method. The domain of the finite element model is smaller due to the computational cost.

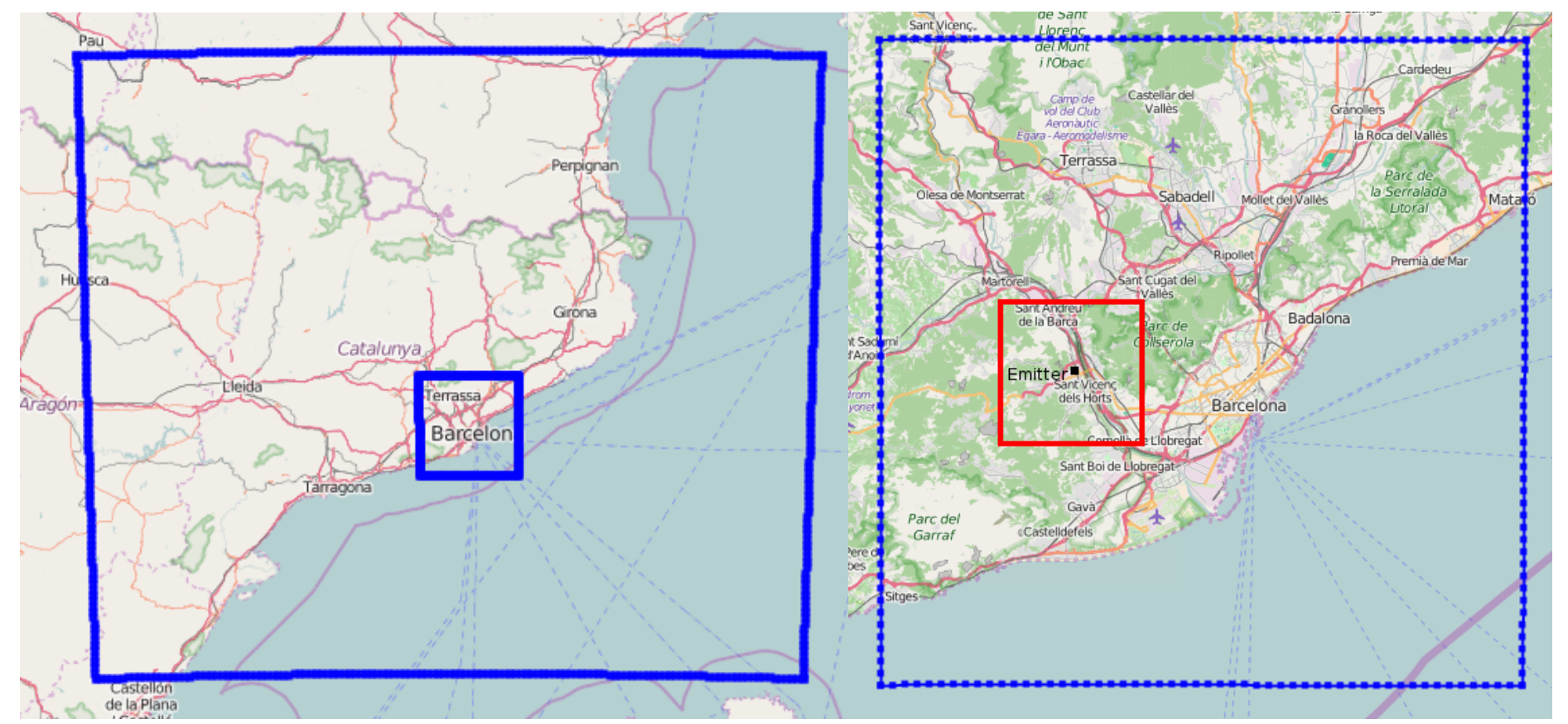

Figure 1. Models domains for simulation (left). Zoom of the inner domain. The red domain is the one used in the finite element model with the emitter position (right).

\section{Emitter characteristics}

The emitter is located at position $416442 \mathrm{~m}, 4584580 \mathrm{~m}$ (UTM 31N). It has a height of $125 \mathrm{~m}$, and a diameter of $4.25 \mathrm{~m}$. The emission of SO2 is $105 \mathrm{t} \mathrm{year}^{-1}$ with a velocity of $10.33 \mathrm{~m} \mathrm{~s}^{-1}$.

\section{Modelling episodes}

The simulations have been carried out on a day with a high concentration of SO2. This criterion has been selected to test the finite element model and to compare the results with the CMAQ system and determine in a high concentration day.

The chosen day is the second of December.

\section{Modelling approach}

Next, we outline the main feature of the two models presented in this work.

\section{WRF-ARW/AEMM/CMAQ}

We have used an Eulerian coupled modeling system (WRF-ARW/AEMM/CMAQ). The mesoscale meteorological model used is Weather Research and Forecasting-Advanced Research (WRF-ARW) version 3.6.1.(Skamarock, 2008), Air Emission Model of Meteosim (AEMM v3.0) is a numerical, deterministic, Eulerian, local-scale model developed by Meteosim S.L. It allows to obtain the intensity of emissions in different areas, either anthropogenic (traffic, industry, residential, etc.) or natural (emissions caused by vegetation or erosion dust) for the area of interest. And the U.S. Environmental Protection 
Agency models-3/CMAQ model is the one used to simulate the physical and chemical processes into the atmosphere. CMAQ is an open-source photochemical model which is updated periodically by the research community. In this contribution we use CMAQ v5.0.1, considering CB-5 chemical mechanism and associated EBI solver (Yarwood, 2005), and AERO5 aerosol module (Carlton, 2010).

For each of the selected days we have run numerical simulations for 48 hours, leaving the first 24 hours as a spin-up to minimize the consequences of taking into account the initial conditions for the start of simulation. The vertical structure of the model includes 32 vertical layers.

\section{Finite Element model}

The finite element model is composed by a mesh generator, a wind mass-consistent model, a plume-rise model, and finally the transport and reaction of pollutants is performed with a finite element method stabilized with Least Squares. The model is coupled with the CMAQ system model in a one-way nesting, i.e. the results from the CMAQ system are used as boundary and initial conditions in the finite element model.

A tetrahedral mesh adapted to the terrain is constructed using the Delaunay-based tetrahedral mesh generator Tetgen (Si, 2015). The mesh incorporates some layers to emulate those in CMAQ.

The wind field is computed interpolating the results from the WRF-ARW simulation, and using a massconsistent model (Oliver, 2015). Once the wind field is computed the plume rise has to be taken into account. Using the Briggs formulation a three-dimensional trajectory of the plume is computed, and the wind field is perturbed so that the pollutants that are emitted follow the trajectory of the plume.

The transport and reaction of pollutants is simulated splitting the transport and the chemistry. The transport is solved using a finite element method stabilized with Least Squares. To solve the system an incomplete Cholesky factorization has been used. The chemical mechanism used is the same used by the CMAQ system. To improve the accuracy of the results and the computational cost an adaptive technique is used. It has been proven for various convection-diffusion problems (Monforte, 2014). To improve the computational cost the model has been parallelized using a multimesh strategy (Monforte, 2013).

\section{PRELIMINARY RESULTS}

In the following sections we describe the results that have been obtained with the two strategies.

\section{WRF-ARW/AEMM/CMAQ model}

The first step to simulate the air quality has been the meteorological simulation using the WRF-ARW. We have simulated the metorological situation using the two nested domains show in Fig. 1 . The result from the simulation has been used to feed the CMAQ simulation. CMAQ uses the same configuration as the WRF simulation. Initial and boundary conditions for the nested domain are provided by the results of the larger domain. Meteorology-Chemistry Interface Processor (MCIP) version 4.1 is used to prepare WRF output to CMAQ model. And AEMM model prepares emissions as AERO5 and CB5 modules require.

\section{Finite element model}

To simulate the air pollution using the finite element model we need to generate a tetrahedral mesh adapted to the terrain. The discretazion of the terrain that we have used is from the shuttle radar topography mission (Farr et al., 2007), specifically the SRTM3 version defined over an uniform grid of 3" $\times 3$ ” (approximately $90 \mathrm{~m} \times 90 \mathrm{~m}$ ). The resulting mesh element size ranges from tens of centimeters to hundreds of meters. In Fig. 3 you can see a detail of the terrain discretization.

With this mesh, the wind field is simulated, and the transport and reactions of pollutants is computed using the results from the CMAQ system modelling as boundary and initial conditions as a one-way nesting.

\section{Comparison}

A comparison between the two simulations has been carried out. 
Figure 2 represents the maximum concentration of SO2 for the selected day, for both simulations. In the CMAQ results we can see how the emitter is not the biggest contribution in the domain. In the Finite Element method results, we can see how the emitter contributes to the pollutant levels, but the boundary conditions also contribute.

To compare the methods we compare the results with observed data from stations. We have chosen two different stations, one near the emitter located at position $416473 \mathrm{~m}, 4583935 \mathrm{~m}$ (UTM 31), and another one far from the emitter located at position 417549m, 4574230m (UTM 31). Figure 3 represents the SO2 levels during the selected day. In the station near the emitter (right) the results from the Finite Element Method is closer to the levels observed, the CMAQ result underpredicts the concentration. In the station distant to the emitter, the results are swapped, being the CMAQ result the one that is closer, almost exact, to the observed levels, while the Finite Element Method underpredicts the concentration.
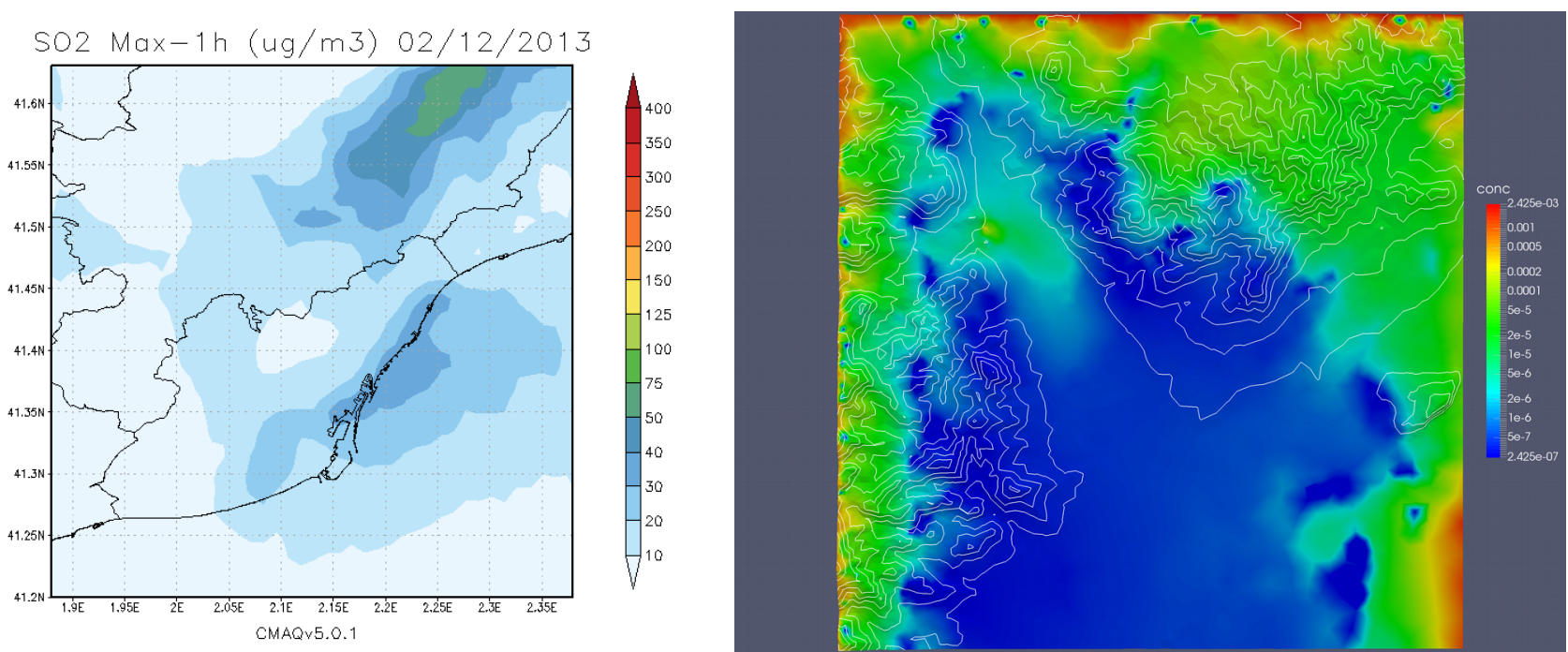

Figure 2. Max. SO2 concentration for chosen day. CMAQ simulation (left) Finite Element Method simulation (right)
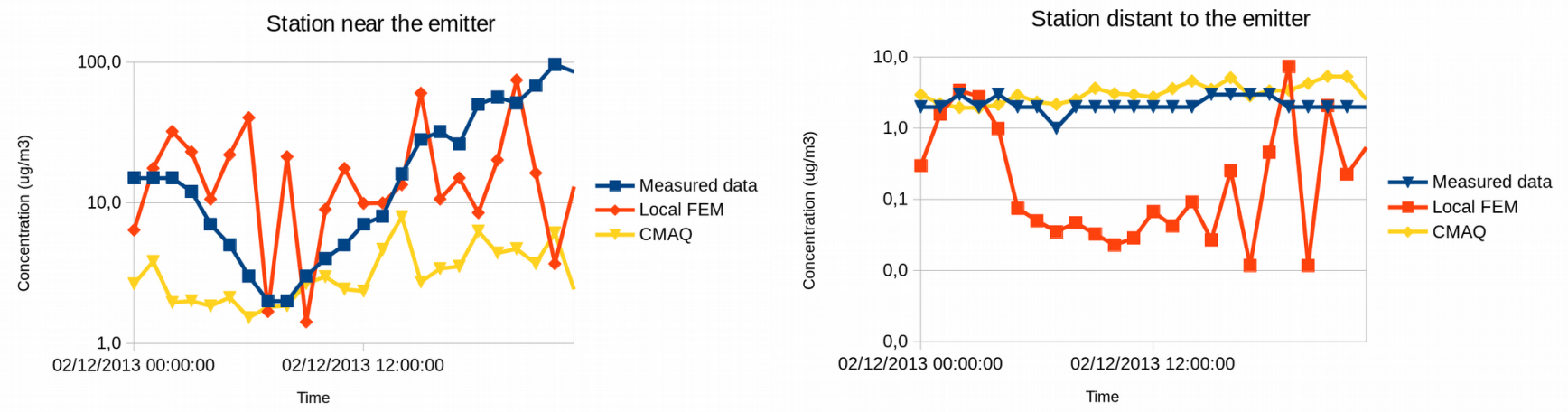

Figure 3. Comparison of concentrations levels in a station near the emitter (left), and a station far from the emitter (right)

\section{CONCLUSIONS}

The preliminar results shown in this abstract are consistent with the expected results. CMAQ is good far from the emitter, while the Finite Element method is better near the emitter. The great swings in the Finite Element method results are a result of the poor wind resolution just one wind field for the whole simulation hour.

More episodes have to be simulated in order to assess the validity of the method, and the coupling of CMAQ and Finite Element Method. 


\section{REFERENCES}

Arasa, R., Picanyol, M., and Solé, J.M., 2013. Analysis of the Integrated Environmental and Meteorological Forecasting and Alert System (SIAM) for Air Quality Applications over Different Regions of the Iberian Peninsula. http://www.harmo.org/Conferences/Proceedings/ Madrid/publishedSections/H15-70.pdf

Arasa, R., Lozano-García, A. \& Codina, B., 2014. Evaluating Mitigation Plans over Traffic Sector to Improve NO2 Levels in Andalusia (Spain) Using a Regional-Local Scale Photochemical Modelling System. OJAP, 03(03). http://dx.doi.org/10.4236/ojap.2014.33008

Arasa, R., Domingo-Dalmau, A. and Vargas, R., 2016. Using a Coupled Air Quality Modeling System for the Development of an Air Quality Plan in Madrid (Spain): Source Apportionment and Analysis Evaluation of Mitigation Measures. Journal of Geoscience and Environment Protection, 04(03). http://dx.doi.org/10.4236/gep.2016.43005

Byun, D. and Schere, K.L., 2006. Review of the Governing Equations, Computational Algorithms, and Other Components of the Models-3 Community Multiscale Air Quality (CMAQ) Modeling System. Appl. Mech. Rev., 59(2). http://dx.doi.org/10.1115/1.2128636

Carlton, A.G. Bhave PV.,. Napelenok, S.L., Edney, E.O., Sarwar, G., Pinder, R.W., Pouliot, G.A., and Houyoux, M., 2010. Model Representation of Secondary Organic Aerosol in CMAQv4.7. Environ. Sci. Technol., 44(22). http://dx.doi.org/10.1021/es100636q

EEA, 2007. Air Pollution in Europe 1990-2004. EEA Report No2/2007. European Environment Agency, Copenhagen

Farr, T.G., ,Rosen, P.A., Caro, E., Crippen, R., Duren, R., Hensley, S., Kobrick, M., Paller, M., Rodriguez, E., Roth, L., Seal, D., Shaffer, S., Shimada, J., Umland, J., Werner, M., Oskin, M., Burbank, D., and Alsdorf, D., 2007. The Shuttle Radar Topography Mission. Reviews of Geophysics, 45(2). http://dx.doi.org/10.1029/2005rg000183

Isakov, V., Irwin, J.S., and Ching, J., 2007. Using CMAQ for Exposure Modeling and Characterizing the Subgrid Variability for Exposure Estimates. Journal of Applied Meteorology and Climatology, 46(9). http://dx.doi.org/10.1175/jam2538.1

Karamchandani, P., 2002. Development and application of a state-of-the-science plume-in-grid model. Journal of Geophysical Research, 107(D19). http://dx.doi.org/10.1029/2002jd002123

Karamchandani, P., Lohman, K., and Seigneur, C., 2008. Using a sub-grid scale modeling approach to simulate the transport and fate of toxic air pollutants. Environ Fluid Mech, 9(1). http://dx.doi.org/10.1007/s10652-008-9097-0

Karamchandani, P., Vijayaraghavan, K., and Yarwood, G., 2011. Sub-Grid Scale Plume Modeling. Atmosphere, 2(4). http://dx.doi.org/10.3390/atmos2030389

Monforte, L. and Pérez-Foguet, A., 2013. A multimesh adaptive scheme for air quality modeling with the finite element method. Int. J. Numer. Meth. Fluids, 74(6). http://dx.doi.org/10.1002/fld.3855

Monforte, L. and Pérez-Foguet, A., 2014. Esquema adaptativo para problemas tridimensionales de convección-difusión. Revista Internacional de Métodos Numéricos para Cálculo y Diseño en Ingeniería, 30(1). http://dx.doi.org/10.1016/j.rimni.2012.11.003

Oliver, A., Montero G., Montenegro R., Rodríguez E., Escobar J.M., Pérez-Foguet A., 2013. Adaptive finite element simulation of stack pollutant emissions over complex terrains. Energy, 49. http://dx.doi.org/10.1016/j.energy.2012.10.051

Oliver, A., Rodríguez, E., Escobar, J.M., Montero, G., Hortal, M., Calvo, J., Cascón, J.M., and Montenegro, R., 2015. Wind Forecasting Based on the HARMONIE Model and Adaptive Finite Elements. Pure Appl. Geophys., 172(1). http://dx.doi.org/10.1007/s00024-014-0913-9

Si, H., 2015. TetGen, a Delaunay-Based Quality Tetrahedral Mesh Generator. TOMS, 41(2). http://dx.doi.org/10.1145/2629697

Rosenbaum, A. The HAPEM5 User's Guide, Hazardous Air Pollutant Exposure Model, Version 5. https://www.epa.gov/sites/production/files/2013-08/documents/hapem5 guide.pdf

Skamarock, W.C. and Klemp, J.B., 2008. A time-split nonhydrostatic atmospheric model for weather research and forecasting applications. Journal of Computational Physics, 227(7). http://dx.doi.org/10.1016/j.jcp.2007.01.037

Yarwood, G., Rao, S., Yocke, M., and Whitten, G.Z., 2005. Updates to the Carbon Bond Chemical Mechanism: CB05. Final Report Prepared for US EPA. http://www.camx.com/publ/pdfs/CB05 Final Report 120805.pdf 